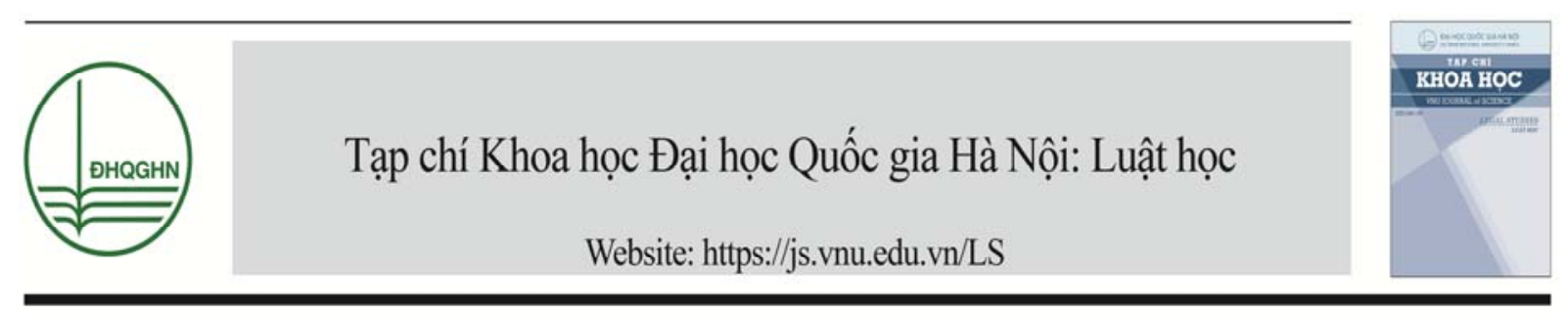

\title{
Cơ chế quản trị đại học tự chủ và yêu cầu hoàn thiện pháp luật tự chủ đại học ở Việt Nam
}

\author{
Đỗ Đức Minh \\ Ban Thanh tra và Pháp chế Đại học Quốc gia Hà Nội, \\ 144 Xuân Thủy, Cầu Giấy, Hà Nội, Việt Nam
}

Ngày nhận 14 tháng 11 năm 2018

Chỉnh sửa ngày 15 tháng 12 năm 2018; Chấp nhận đăng ngày 24 tháng 12 năm 2018

Tóm tắt: Bài viết làm rõ những vấn đề cơ bản về cơ chế quản trị đại học tự chủ, khái quát tiến trình thể chế hóa chủ trương tự chủ đại học và triển khai thực hiện tự chủ đại học trong thời gian qua, phân tích những hạn chế, bất cập của phápluật và làm rõ nhu cầu hoàn thiện pháp luật về tự chủ đại học, đáp ứng yêu cầu đổi mới căn bản, toàn diện giáo dục đại học hiện nay.

Tù khóa: Tự chủ đại học, Đổi mới giáo dục đại học, Việt Nam.

\section{Cơ chế quản trị đại học tự chủ}

\subsection{Tụ chủ đại hoc (university autonomy)}

Tự chủ đại học $(\mathrm{TC} H \mathrm{H})$ là quyền tự do của trường đại học trong việc quyết định những công việc của chính mình; thể hiện khả năng chủ động trong việc xây dựng và thực hiện chiến lược của nhà trường mà không bị trói buộc bởi những quy định và quản lí ở cấp vĩ mô. Là khả năng toàn diện của trường đại học hoạt động theo cách thức lựa chọn để đạt được sứ mệnh và mục tiêu được đặt ra, tự chủ cũng mang lại những lợi thế cho các trường đại học bởi một nguyên lí cơ bản đằng sau tự chủ là các cơ sở giáo dục đại học (GDĐH) sẽ vận hành tốt hơn.

*ĐT.: 84-24-37547016.

Email:minhdd@vnu.edu.vn.

https://doi.org/10.25073/2588-1167/vnuls.4183
Quyền tự chủ đại học được phân biệt thành 2 dạng thức [1]:

1) Tư chủ thục chất hay bản thể (substantive autonomy) - là quyền của nhà trường được tự xác định các mục tiêu, chương trình của mình để trả lời câu hỏi dạy "cái gì"? và điều này được thể hiện ở tuyên bố sứ mạng của nhà trường (các trường đại học có quyền tuyên bố sứ mạng và các mục tiêu, cách thức đi đến mục tiêu mà không phụ thuộc vào bất cứ sự can thiệp nào từ chính phủ và các cơ quan quản lí). Đó chính là thẩm quyền đầy đủ của trường đại học trong loại hình tổ chức của mình để đưa ra các quyết định chương trình, mục tiêu (cái học thuật) và vận hành nhà trường.

2) Tư chủ thu tuc (procedural autonomy) [2] - là quyền của nhà trường được xác định các biện pháp thi hành để theo đuổi các mục tiêu và chương trình đã vạch ra (cách học thuật). Đó 
chính là thẩm quyền của trường đại học trong loại hình tổ chức của mình để thực hiện các quyết định sã̃n có (dạy học "như thế nào") nhưng không có quyền đưa ra quyết định. Hạt nhân của khái niệm tự chủ là văn hóa quản lí phân cấp, phân quyền (decentralization) về trách nhiệm công việc và trách nhiệm giải trình (hay trách nhiệm xã hội - accountability) trong học thuật và thực hiện các chức năng quản lí.

"Trường đại học là một tổ chức tự chủ trong trái tim của các xã hội"1. Một trường đại học cần phải là cơ sở giáo dục tự chủ để thỏa mãn nhu cầu của thế giới xung quanh nó. Là đặc tính vốn có, bản chất cốt lõi của giáo dục, tự chủ đại học (TCĐH) là điều kiện thiết yếu để thực hiện các phương thức quản trị đại học tiên tiến tạo động lực để các trường đổi mới nhằm cải tiến nâng cao chất lượng đạt hiệu quả cao hơn hoạt động, làm gia tăng tính cạnh tranh giữa các cơ sở GDĐH và đa dạng hóa các hoạt động giáo dục. Quyền tự chủ một mặt đảm bảo cho trường đại học được tự quyết định các vấn đề của mình nhưng mặt khác cũng đề cao trách nhiệm xã hội (TNXH) của nhà trường. Xu hướng chung trong đổi mới GDĐH trên thế giới hiện nay là chuyển dịch dần từ mô hình nhà nước kiểm soát sang các mô hình có mức độ tự chủ cao hơn, từ mô hình đại học do nhà nước kiểm soát sang mô hình nhà nước giám sát chất lượng. Việc tạo môi trường cho phép các trường tự quyết và chịu trách nhiệm được nhiều chính phủ lựa chọn như là giải pháp để ứng phó trước sức ép tài chính và sự thay đổi nhanh của nền kinh tế. Vai trò mạnh mẽ truyền thống của nhà nước được nhận thức lại, thay vì kiểm soát chi tiết nhà nước có thể tăng cường giám sát và can thiệp thận trọng trong quản lí các trường. Khuynh hướng này cũng làm giảm giá trị truyền thống của mối quan hệ nhà nước và trường đại học. Theo đó, việc tăng quyền lực ở cấp trường đại học cũng đồng nghĩa với giảm bớt quyền lực của cơ quan quản lí Nhà nước (như Bộ GD\&ĐT).

\footnotetext{
${ }^{1}$ Trong diễn ngôn GDĐH của các nước phương Tây, tụ chủ là một khái niệm rất quan trọng và được xem là một giá trị căn bản của một trường đại học, như đã được tái khẳng định trong Tuyên bố Magna Charta Universitatum tại Bologna 1988.
}

\subsection{Các thành tố của tư chủ đại học}

Tự chủ đại học (TCĐH) được hiểu là sự chủ động trong quản lí của tổ chức trường đại học mang tính pháp lí về các mặt sau đây:

- Tư chủ trong học thuật (academic freedom): là sự tự do của cơ sở GDĐH trong việc quyết định những vấn đề thuộc về học thuật như: ngành học và chương trình đào tạo, tài liệu giảng dạy, các tiêu chuẩn học thuật và chất lượng, phương pháp sư phạm, số lượng và phương thức tuyển sinh, kĩ thuật đánh giá kết quả học tập của sinh viên; quyền của trường được tự do lựa chọn thầy giáo,... Ở phương diện cá nhân, tự do học thuật là quyền được tự do lựa chọn nội dung giảng dạy, theo đuổi tri thức và công bố các kết quả nghiên cứu của giảng viên và sinh viên mà không bị can thiệp vô lí hay bị giới hạn bởi luật pháp, các quy định của cơ sở giáo dục hay áp lực của công chúng; là quyền của giáo chức đại học "không bị ràng buộc bởi bất kì giáo lí định sẵn nào, về tự do giảng dạy và thảo luận, tự do tiến hành nghiên cứu, phổ biến và xuất bản kết quả nghiên cứu, tự do bày tỏ ý kiến của mình về tổ chức hoặc hệ thống trong đó họ làm việc, tự do thoát khỏi kiểm duyệt của nhà trường và tham gia các tổ chức nghề nghiệp hay các cơ quan đại diện học thuật" [3]. Việc nghiên cứu và giảng dạy cần phải độc lập về mặt đạo đức, trí tuệ đối với các quyền lực chính trị và sức mạnh kinh tế. Về bản chất, tự do học thuật là sự chủ động trong hoạt động đào tạo và $\mathrm{NCKH}$ của nhà trường trên cơ sở tự trị về quản lí mà cốt lõi là toàn quyền tự quyết trong việc lựa chọn chương trình giảng dạy, nghiên cứu và bổ nhiệm nhân sự theo hướng tự do học thuật của nhà trường.

Là giá trị cốt lõi của đại học, tự do học thuật (tự do nghiên cứu và tự do giảng dạy) trở thành tinh thần xuyên suốt của mọi hoạt động của trường đại học. Từ tinh thần tự do học thuật, trường đại học trở thành nơi khai phá, nuôi dưỡng, truyền bá và xiển dương tri thức; cũng không chỉ là một trung tâm tri thức mà còn là một trung tâm văn hóa. Trong thời đại kinh tế tri thức của thế kỷ XXI, trường đại học trở thành cỗ máy then chốt của xã hội tri thức thì tự 
do học thuật càng quan trọng và ý nghĩa đối với hiệu quả hoạt động của nhà trường cũng như để tạo nên một xã hội dân sự lành mạnh và phát triển đời sống tri thức.

- Tứ chủ về tổ chức và quản lí hay tự chủ trong quản trị (organizational autonomy): là sự tự do của cơ sở đào tạo trong việc sắp xếp và tổ chức các sự kiện, các mối quan hệ liên quan đến lập kế hoạch, tổ chức và điều phối để thúc đẩy sự năng động, phát triển của từng cá nhân và sự vững mạnh của cơ sở GDĐH. Các trường đại học cần được tự quyết định và chủ động xây dựng cơ cấu tổ chức, phân chia, thành lập các đơn vị trực thuộc, tuyển dụng, bổ nhiệm, đãi ngộ nhân tài hoặc xây dựng chiến lược phát triển có tầm nhìn và định hướng rõ ràng. Về bản chất, đó là sự chủ động về các cách thức quản lí nguồn lực bên trong của nhà trường nhằm mục tiêu phát triển.

- Tụ chủ về tài chính (financial autonomy): là sự tự do của cơ sở đào tạo trong sử dụng các nguồn lực tài chính theo chiến lược ưu tiên lựa chọn, bao gồm các vấn đề tài chính như: phân bổ kinh phí, cung cấp tài chính tự nguyện, vận hành tài chính và trách nhiệm giải trình. "Định nghĩa sủ dụng được về tự chủ đại học là sư không phu thuộc vào một nguồn hồ trọ duy nhất và chật hẹp nào cả"2. Về bản chất, đó là sự chủ động về việc đảm bảo các nguồn lực bên trong phục vụ các hoạt động đào tạo và NCKH của trường. Cơ sở cung cấp tài chính đa dạng và thẩm quyền sử dụng, tạo nguồn thu, quyền quyết định độc lập về sử dụng ngân sách được nhà nước cấp cũng như quyền được tạo quỹ từ những nguồn khác được xem là những vấn đề cốt lõi của tự chủ tài chính. Các trường đại học cần được tự quyết định và chủ động khai thác, tìm kiếm các nguồn tài chính; cách thức sử dụng các nguồn tài chính và tài sản hiện có, đầu tư cho tài sản tương lai và cân đối thu - chi nhằm đảm bảo hệ thống tài chính minh bạch, tuân thủ pháp luật và không vụ lợi.

"Trong bối cảnh mô hình đại học truyền thống đang trở nên lỗi thời và đang được thay thế bằng mô hình đại học mới, khi nguồn lực

$\overline{2}$ Định nghĩa của Babbidge và Rosenweig năm 1962. đầu tư của Nhà nước cho giáo dục hạn hẹp, việc trao quyền tự chủ đầy đủ cho các trường đại học là biện pháp hữu hiệu nhất để phát triển GDĐH”. Do sự chia sẻ ngân quỹ công cho GDĐH đang giảm sút và nhà nước đang đòi hỏi GDĐH phải làm nhiều hơn với chi phí thấp hơn cho nên việc đa dạng hóa nguồn thu sẽ mở rộng mức độ tự chủ của nhà trường. Sự đa dạng của cơ sở ngân quỹ là điều cốt yếu để tạo ra những thay đổi mang tính hệ thống. Một nguồn tài chính đa dạng là một phần của TCĐH và do sự mở rộng cơ sở tài chính, TCĐH trở nên rộng hơn.

Trên quan điểm hệ thống, sự chủ động của các trường đại học về các phương diện học thuật (chuyên môn), tài chính và tổ chức quản lí là không thể tách rời nhằm trao quyền "tự chủ toàn diện" cho các cơ sở $\mathrm{GDĐH}^{3}$. Với những chủ động trên, các trường đại học vừa đạt được mục tiêu phát triển bền vững trong lâu dài vừa thúc đẩy sự cạnh tranh năng động và lành mạnh nhằm nâng cao sự đóng góp của hệ thống GDĐH với sự phát triển của quốc gia.

\subsection{Tư chủ đại học-xu thế tất yếu của giáo duc đại học}

Tự chủ đại học là yêu cầu hàng đầu trong quá trình đổi mới GDĐH trên toàn thế giới hiện nay, được khẳng định nhưmột công cụ quan trọng trong việc tạo nguồn lực để phục vụ các hoạt động cần thiết của một trường đại học và làm tròn sứ mệnh của nó đối với xã hội. Trên thực tế, sau khi gia nhập WTO (11/01/2007), Việt Nam đã tham gia vào quá trình toàn cầu hóa trong đó có cả giáo dục, nghĩa là GDĐH Việt Nam cũng "buộc phải hoạt động trong một môi trường cạnh tranh trên mọi phương diện". Hệ thống GDĐH Việt Nam được duy trì rất lâu trong cơ chế quản lí toàn diện cần được chuyển sang cơ chế quản lí mới, bình đẳng và rõ ràng hơn. Tuy nhiên, kết quả của cách làm cũ rõ ràng

\footnotetext{
${ }^{3}$ Bởi lẽ: các nội dung của tự chủ liên quan chặt chẽ với nhau, nếu không có được quyền tự chủ trong mặt này thì quyền tự chủ ở các mặt khác không thể phát huy đầy đủ được. Như: khi được giao tự chủ về tài chính thì cần được giao quyền chủ động trong tuyển sinh, xây dựng mức thu học phí và các khoản thu....
} 
là chưa được như mong muốn của xã hội, đặc biệt là trong khi nhu cầu học đại học đã trở thành đại chúng. Không ngoài quy luật phát triển, khi hệ thống các trường đại học ngày càng đa dạng về sở hữu và gia tăng nhanh chóng về số lượng thì cách thức quản lí theo cơ chế bao cấp đã không còn phù hợp và nếu không thực hiện TCĐH theo lộ trình thì GDĐH Việt Nam không thể hoàn thành được sứ mệnh của mình. Vai trò của quản lí nhà nước cần được tách bạch từ vai trò quản lí vi mô sang quản lí vĩ mô mang tính định hướng và điều phối. Từ thực tế này, Việt Nam cần có một cuộc cách mạng trong GDĐH và chấn hưng giáo dục là mệnh lệnh cuộc sống. Đổi mới GDĐH là yêu cầu bức thiết và tự chủ chính là giải pháp chiến lược cho GDĐH; các trường đại học (trước hết là các trường công lập) cần phải chuyển đổi nhanh chóng sang cơ chế tự chủ và chịu TNXH. Vì vậy, những năm đầu của thế kỷ XX cùng với sự xuất hiện khái niệm tự chủ, tự chịu trách nhiệm đã thu hút sự quan tâm và tranh luận của xã hội, ngành giáo dục đã bước vào công cuộc đổi mới mang tính bước ngoặt và đột phá về cơ chế quản lí GDĐH. Đồng thời, quá trình đổi mới (cải cách) theo hướng trao quyền tự chủ cho các trường đại học cũng hướng tới xây dựng và hoàn thiện hệ thống pháp luật rành mạch, thống nhất, bình đẳng và triển khai các chính sách hỗ trợ phù hợp, nhất quán cho các loại hình trường tham gia cung cấp sản phẩm, dịch vụ GDĐH một cách thuận lợi và chủ động.

\section{Tiến trình xây dựng pháp luật tự chủ đại học ở Việt Nam}

Từ phương diện pháp lí, TCĐH được xem là khả năng hành động chủ động mang tính pháp lí về các mặt học thuật, tài chính, tổ chức và nhân sự của tổ chức trường đại học; là phương thức quản trị đại học tiên tiến nhằm cải tiến, nâng cao chất lượng đào tạo, đã được khẳng định là một công cụ quan trọng trong việc tạo nguồn lực để giúp các trường thực hiện tốt sứ mệnh của mình đối với xã hội. Thực hiện cơ chế quản trị tự chủ cũng là một yêu cầu hàng đầu trong quá trình đổi mới GDĐH Việt Nam hiện nay nhằm đáp ứng yêu cầu đào tạo nguồn nhân lực trình độ cao trong thời kì đẩy mạnh công nghiệp hóa, hiện đại hóa và hội nhập quốc tế. Trong 2 thập kỷ qua, các trường đại học Việt Nam từng bước được trao quyền tự chủ, được thể hiện qua các đạo luật giáo dục và văn bản pháp quy của Nhà nước, nhu:

\subsection{Quyền tụ chủ qua Luât Giáo dục và các văn bản pháp quy của Nhà nước}

Thực hiện chủ trương đổi mới GDĐH, Luật Giáo dục, Điều lệ nhà trường và nhiều văn bản quy phạm pháp luật (VBQPPL) được ban hành nhằm trao quyền tự chủ, tự chịu trách nhiệm cho các đơn vị sự nghiệp đào tạo công lập. Cụ thể là:

- Luật Giáo dục năm 1998 (Luật số 11/1998/QH10) đánh dấu sự chuyển biên tích cực trong nhận thức của các cấp quản lí về TCĐH bằng sự ghi nhận quyền tự chủ và tự chịu trách nhiệm của trường cao đẳng, trường đại học với các nội dung:

1) Xây dựng chương trình, giáo trình, kế hoạch giảng dạy, học tập đối với các ngành nghề được phép đào tạo;

2) Tổ chức tuyển sinh theo chỉ tiêu của Bộ Giáo dục và Đào tạo, tổ chức quá trình đào tạo, công nhận tốt nghiệp và cấp văn bằng theo thẩm quyền;

3) Tổ chức bộ máy nhà trường;

4) Huy động, quản lí, sử dụng các nguồn lực nhằm thực hiện mục tiêu giáo dục;

5) Hợp tác với các tổ chức kinh tế, giáo dục, văn hoá, thể dục, thể thao, $\mathrm{y}$ tế, nghiên cứu khoa học $(\mathrm{NCKH})$ trong nước và nước ngoài theo quy định của Chính phủ (Điều 55). Những quyền này thuộc 4 nhóm quyền có tính khung về học thuật, tổ chức và nhân sự, nguồn lực vật chất và về hợp tác.

- Nghị định số 31-CP và Nghị định số 32$C P$ ngày 4/4/1994 của Chính phủ về việc thành lập lập Đại học Thái Nguyên và Đại học Đà Nẵng không ghi nhận quyền tự chủ nào. Như vậy, quyền tự chủ của đại học vùng được xác 
lập chung với loại hình trường đại học theo Điều lệ Trường đại học.

- Điều lẹ trường đại học ban hành theo Quyết định số 153/2003/QĐ-TTg, ngày 30/7/2003 của Thủ tướng Chính phủ nêu rõ: “Trường đại học được quyền tự chủ và tự chịu trách nhiệm theo quy định của pháp luật và Điều lệ trường đại học về quy hoạch, kế hoạch phát triển nhà nước, tổ chức hoạt động đào tạo, KH\&CN, tài chính, quan hệ quốc tế, tổ chức và nhân sự" (Điều 10). Điều lệ quy định 7 nhóm quyền tự chủ đối với loại hình trường trường đại học, gồm: 1) hoạch định phát triển; 2) xây dựng chương trình, giáo trình, kế hoạch đào tạo, tuyển sinh, tổ chức đào tạo, công nhận tốt nghiệp, in ấn và cấp bằng; 3 ) huy động, quản lí, sử dụng các nguồn lực, hợp tác và liên kêt nâng cao chất lượng và sự phù hợp; 4) đăng ký tham gia tuyển chọn, thực hiện nhiệm vụ và ký kết hợp đồng khoa học công nghệ; 5) hợp tác, liên doanh, nhận tài trợ, góp vốn, sử dụng nguồn thu ngoài ngân sách; 6) nhận đất, thuê đất, vay vốn; và 7$)$ tổ chức bộ máy nhà trường.

- Luật Giáo duc năm 2005 (Luật số 38/2005/QH11) xác lập quyền tự chủ và TNXH của cơ sở GDĐH, ghi nhận quyền tự chủ của trường đại học với nội dung tương tự quan niệm của các nước phát triển, thể hiện tập trung ở những quy định về thực hiện phân công, phân cấp quản lí giáo dục, tăng cường quyền tự chủ, tự chịu trách nhiệm của cơ sở giáo dục; khẳng định "Nhà nước ... sẽ tăng cường quyền tự chủ, tự chịu trách nhiệm của cơ sở giáo dục" (Điều 14) và quyền tự chủ và tự chịu trách nhiệm của trường trung cấp, trường cao đẳng, trường đại học (Điều 60) .

\footnotetext{
$\overline{4}$ Điều 60 (Luật Giáo dục 2005) quy định: “Trường trung cấp, trường cao đẳng, trường đại học được quyền tự chủ và tự chịu trách nhiệm theo quy định của pháp luật và theo Điều lệ nhà trường trong các hoạt động: 1) Xây dựng chương trình, giáo trình, kế hoạch giảng dạy, học tập đối với các ngành nghề được phép đào tạo; 2 ) Xây dựng chỉ tiêu tuyển sinh, tổ chức tuyển sinh, tổ chức quá trình đào tạo, công nhận tốt nghiệp và cấp văn bằng; 3 ) Tổ chức bộ máy nhà trường; tuyển dụng, quản lí, sử dụng, đãi ngộ nhà giáo, cán bộ, nhân viên; 4) Huy động, quản lí, sử dụng các nguồn lực; 5) Hợp tác với các tổ chức kinh tế, giáo dục,
}

- Nghi quyết số $14 / 2005 / N Q-C P$ ngày 02/11/2005 của Chính phủ về đổi mới cơ bản và toàn diện GDĐH Việt Nam giai đoạn 2006 2020 cũng khẳng định tầm quan trọng của việc hoàn thiện chính sách phát triển GDĐH theo hướng bảo đảm quyền tự chủ và trách $\mathrm{TNXH}$ của cơ sở GDĐH, quản lí của Nhà nước và vai trò giám sát của xã hội đối với GDĐH. Đổi mới cơ chế quản lí cần chuyển các cơ sở GDĐH công lập sang hoạt động theo cơ chế tự chủ, có pháp nhân đầy đủ, có quyền quyết định và chịu trách nhiệm về đào tạo, nghiên cứu, tổ chức, nhân sự và tài chính; xóa bỏ cơ chế bộ chủ quản, xây dựng cơ chế đại diện sở hữu nhà nước đối với các cơ sở GDĐH công lập.

- Nghi dịnh 43/2006/ND-CP ngày $25 / 4 / 2006^{5}$ của Chính phủ quy định quyền tự chủ, tự chịu trách nhiệm về thực hiện nhiệm vụ, tổ chức bộ máy, biên chế và tài chính đối với đơn vị sự nghiệp công lập. Nghị định này được ban hành nhằm tạo điều kiện cho các đơn vị sự nghiệp công lập nói chung, cơ sở GDĐH công lập nói riêng vượt qua những thách thức trong thực hiện cơ chế tự chủ, thúc đẩy phát triển sự nghiệp GDĐH, nâng cao chất lượng dịch vụ, cho phép các đơn vị sự nghiệp đào tạo công lập tìm kiếm biện pháp mở rộng hoạt động dịch vụ, tăng nguồn thu, chi tiêu tiết kiệm để hoàn thành tốt nhiệm vụ được giao. Trên cơ sở cho phép huy động sự đóng góp và tham gia tích cực của cộng đồng xã hội cho phát triển GDĐH, tăng nguồn thu sự nghiệp và tăng thu nhập cho công chức, viên chức cũng như tăng cường tính công khai minh bạch, dân chủ trong các quyết định và hoạt động của nhà trường, Nghị định góp phần nâng cao tính chủ động, sáng tạo các trường đại học công lập.

- Quyết định 121/2007/QD-TTg ngày 27/7/2007 của Thủ tướng Chính phủ phê duyệt mạng lưới các trường đại học và cao đẳng giai đoạn 2006 - 2020, trong đó có xác định các trường trọng điểm (14 trường). Quyền tự chủ

văn hóa, thể dục, thể thao, y tế, NCKH trong nước và nước ngoài theo quy định của Chính phủ”.

${ }^{5}$ Nghị định này được hình thành và khởi nguồn từ Nghị định 10/2002/NĐ-CP ngày 16/01/2002 về việc thực hiện thí điểm chế độ tài chính áp dụng cho đơn vị sự nghiệp có thu. 
của trường trọng điểm được trao theo phương thức đặc biệt, mang tính cục bộ và cá biệt mà theo trù tính là đề thực hiện vai trò đầu đàn trong hệ thống GDĐH, là tổ chức khoa học công nghệ mạnh cũng như có đủ năng lực tiếp nhận và sử dụng hiệu quả vốn đầu tư tập trung. Việc tăng cường quyền tự chủ nhằm tạo thuận lợi cho các trường thực hiện chính sách ưu tiên của Chính phủ.

- Thông tu liên tịch 07/2009/TTLT-BGDĐT$B N V$ của Bộ GD\&DT và Bộ Nộ vu ngày $15 / 4 / 2009$ hướng dẫn quyền tự chủ, tự chịu trách nhiệm về việc thực hiện nhiệm vụ, tổ chức bộ máy, biên chế đối với đơn vị sự nghiệp công lập GD\&ĐT đã nêu rõ quyền tự chủ của đơn vị trong việc xác định nhiệm vụ xây dựng kế hoạch và tổ chức thực hiện; tổ chức bộ máy và biên chế trong đơn vị; việc tuyển dụng, quản lí và sử dụng cán bộ, công chức, viên chức.

- Quyết định số 380/QD-TTg ngày 24/3/2009 và Quyết định số 391/QĐ-TTg ngày $31 / 3 / 2017$ của Thủ tướng Chính phủ ban hành quy chế về tổ chức và hoạt động của Trường đại học Việt - Đức và Trường Đại học Việt Nhật. Theo đó, quyền tự chủ của đại học quốc tế được xác lập đầy đủ nhất, cả quyền tự chủ tổ chức và quyền tự do học thuật với quy chế tổ chức và hoạt động riêng biệt (trường được tự quyết định các công việc nội bộ và tự chủ cao trong học thuật) nhằm thực hiện yêu cầu chính sách $\mathrm{GDĐH}^{6}$. So với các quy định về tự chủ trước, quyền tự do học thuật được ghi nhận khá rõ ràng, cho thấy sự thay đổi tư duy bước đầu về trao quyền tự chủ triệt để cho trường đại học công.

- Nghị quyết số 05-NQ/BCSÐ của Ban cán sư Đảng Bộ GD\&ĐT ngày 06/01/2010 về đổi mới GDĐH giai đoạn 2010-2012 khẳng định thực hiện quyền tự chủ, tự chịu trách nhiệm về thực hiện nhiệm vụ, tổ chức bộ máy, biên chế đối với đơn vị sự nghiệp công lập trong GD\&ĐT; tăng cường quyền tự chủ, tự chịu

\footnotetext{
$\overline{{ }^{6}}$ Nội dung các quyền trong từng mặt được quy định rõ ràng cả về tự chủ thực chất và thủ tục; chỉ bị giới hạn bởi trách nhiệm "xuất sắc", nghĩa vụ "công khai, giải trình, báo cáo cơ quan chủ quản”.
}

trách nhiệm và kiểm soát bên trong của trường đại học phù hợp với các quy định của Nhà nước. Nghị quyết xác định các giải pháp cụ thể, như: phát huy cao độ tính tự chủ, tự chịu trách nhiệm, tự kiểm soát bên trong của các trường; tăng cường giám sát và kiểm tra của nhà nước, xã hội và bản thân các trường; nhấn mạnh cơ chế thủ trưởng các cơ sở GDĐH quyết định bậc lương của giảng viên theo sự cống hiến của họ và kết quả đánh giá hoạt động giảng dạy hàng năm.

- Chi thi 296/CT-TTg ngày 27/02/2010 của Thủ tướng Chính phủ về đồi mới quản lí giáo dục trong giai đoạn 2010-2012 nêu rõ việc đổi mới quản lí GDĐH (gồm quản lí nhà nước về giáo dục và quản lí của các cơ sở đào tạo) là khâu đột phá để đổi mới toàn diện của GDĐH. Thủ tướng cũng giao cho Bộ GD\&ĐT rà soát, bổ sung, điều chỉnh VBQPPL đã ban hành; xây dựng các $\mathrm{VBQPPL}$ mới về thành lập trường, tuyển sinh, tổ chức đào tạo, quản lí tài chính, quản lí chất lượng, tuyển dụng, làm rõ trách nhiệm và chế độ của nhà giáo trong đào tạo và $\mathrm{NCKH}$, quan hệ giữa Ban giám hiệu, Hội đồng trường, Đảng ủy, các đoàn thể ở trường... Trên cơ sở đó, các trường đại học, cao đẳng thực hiện quyền tự chủ và nghĩa vụ tự chịu trách nhiệm trước xã hội và nhà nước theo Luật Giáo dục.

Ngoài ra, từ năm 2006-2007 ngành giáo dục và các bên có liên quan cũng xây dựng một số đề án trao quyền tự chủ cho các trường đại học nếu các trường thỏa mãn 5 tiêu chí về đảm bảo chất lượng, kiểm định chất lượng, kiểm toán thường xuyên, công bố mức học phí, chương trình đào tạo và phù hợp với quy hoạch. Nhìn chung, việc trao quyền tự chủ, cho các đơn vị sự nghiệp (đặc biệt là khối GDĐH) ngày càng được quan tâm.

2.2. Quyền tư chủ của co sở giáo duc đại học theo Luật Giáo dục đại học năm 2012 và Nghị dinh 186/2013/ND-CP

Ngày 18/6/2012, tại kì họp thứ 3, Quốc hội khóa XII đã thông qua Luật GDĐH (Luật số 08/2012/QH13) gồm 12 chương, 73 điều, có hiệu lực thi hành từ ngày $01 / 01 / 2013$. Luật 
GDĐH được ban hành nhằm mục tiêu thể chế hóa các chủ trương chính sách của Đảng - Nhà nước về giáo dục, tạo cơ sở pháp lí vững chắc, thống nhất cho sự phát triển của GDĐH và thực hiện các mục tiêu giáo dục ${ }^{7}$. Luật quy định về tổ chức, nhiệm vụ, quyền hạn của cơ sở GDĐH, các hoạt động đào tạo và hợp tác quốc tế, bảo đảm chất lượng và kiểm định chất lượng GDĐH, giảng viên. Đây là sự kiện có ý nghĩa quan trọng nhằm hoàn thiện cơ sở pháp lí, nâng cao chất lượng tổ chức và hoạt động GDĐH, đổi mới quản lí GDĐH, tạo điều kiện cho sự nghiệp giáo dục phát triển mạnh mẽ hơn. Luật GDĐH 2012 một lần nữa khẳng định quyết tâm thực hiện những cải cách theo hướng tăng quyền tự chủ các trường đã được nêu tại Luật giáo dục 2005, là một bước tiến quan trọng trong tư duy QTĐH Việt Nam vốn rất quen thuộc với sự chỉ đạo và kiểm soát chặt chẽ của Bộ GD\&ĐT đối với các trường cũng như với các giảng viên và người học. Luật quan tâm nhiều đến vấn đề tự chủ của cơ sở GDĐH và đã khẳng định quyền tự chủ của các trường đại học trong một điều luật riêng (Điều 32). Lần đầu tiên quyền tự chủ của trường đại học được đưa vào văn bản pháp luật và sự kiện này được xem là một bước phát triển về cơ chế quản trị đại học nước ta. Ngoài ra, quyền TCĐH cũng được thể hiện ở nhiều điều khoản của Luật về Hội đồng trường, Hội đồng quản trị, Hiệu trưởng, nhiệm vụ và quyền hạn của cơ sở giáo dục, tuyển sinh, chương trình giáo dục, văn bằng, học phí, lệ phí tuyển sinh.Các cơ sở GDĐH được tự chủ trong các hoạt động chủ yếu thuộc các lĩnh vực tổ chức và nhân sự, tài chính và tài sản, đào tạo, khoa

\footnotetext{
${ }^{7}$ Như: đổi mới quản lí nhà nước về GDĐH và đổi mới quản lí của cơ sở giáo dục, nâng cao chất lượng GDĐH, góp phần đổi mới cơ bản và toàn diện GDĐH; đổi mới và nâng cao chất lượng công tác quản lí giáo dục và cán bộ quản lí GDĐH; đẩy mạnh phân cấp quản lí GDĐH và thực hiện quyền tự chủ, tự chịu trách nhiệm của cơ sở GDĐH phù hợp với năng lực quản lí, năng lực tổ chức hoạt động giáo dục và TNXH; đầy mạnh xã hội hóa giáo dục, huy động các nguồn đầu tư phát triển GDĐH; tạo điểu kiện pháp lí để cải tiến mạnh mẽ chương trình, nội dung và phương pháp giảng dạy, đẩy mạnh đổi mới nội dung, chương trình và phương pháp giáo dục theo hướng khoa học, hiện đại, tiên tiến và thiết thực, phù hợp với thực tiễn Việt Nam.
}

học và công nghệ, hợp tác quốc tế, bảo đảm chất lượng GDĐH; tự chủ quyết định phương thức tuyển sinh, chịu trách nhiệm về công tác tuyển sinh; chịu trách nhiệm công bố công khai chỉ tiêu tuyển sinh, chất lượng đào tạo và các điều kiện bảo đảm chất lượng đào tạo; tự chủ, tự chịu trách nhiệm trong xây dựng, thẩm định, ban hành chương trình đào tạo trình độ cao đẳng, đại học, thạc sĩ, tiến sĩ... Để gắn chất lượng đào tạo với tên tuồi của nhà trường, Luật cũng quy định cơ sở GDĐH được tự chủ xác định và thực hiện chỉ tiêu tuyển sinh, xây dựng và thực hiện chương trình giáo dục, đánh giá kêt quả học tập và công nhận tốt nghiệp, in phôi văn bằng, cấp văn bằng cho người học.

Khẳng định quyền tự chủ là một thuộc tính của cơ sở GDĐH, Luật đã trao quyền tự chủ ở mức tối đa phù hợp với năng lực và điều kiện đảm bảo thực hiện quyền tự chủ của các cơ sở GDĐH.Nhằm đánh giá uy tín, chất lượng đào tạo phục vụ công tác quản lí Nhà nước và ưu tiên đầu tư ngân sách Nhà nước, các cơ sở GDĐH sẽ được phân tầng, xếp hạng dựa trên các tiêu chí chính ${ }^{8}$. Cơ sở GDĐH thực hiện quyền tự chủ ở mức độ cao hơn phù hợp với năng lực, kết quả xếp hạng và kiểm định chất lượng giáo dục. Triết lí chính và tư tưởng nhất quán, xuyên suốt trong các quy định của Luật là trao quyền tự chủ phù hợp với năng lực thực hiện của các cơ sở GDĐH, theo sự phân tầng, xếp hạng đại học ${ }^{9}$; gắn với cam kết chịu trách nhiệm của cơ sở GDĐH và lộ trình thích hợp. Tự chủ đảm bảo sự năng động sáng tạo nhưng

\footnotetext{
${ }^{8}$ Như: vị trí, vai trò trong hệ thống GDĐH; quy mô, ngành nghề và các trình độ đào tạo, cơ cấu các hoạt động đào tạo và khoa học công nghệ, chất lượng đào tạo và NCKH...

${ }^{9}$ Điều 32 quy định: 1 . Cơ sở GDĐH tự chủ trong các hoạt động chủ yếu thuộc các lĩnh vực tổ chức và nhân sự, tài chính và tài sản, đào tạo, KH\&CN, HTQT, bảo đảm chất lượng GDĐH. Cơ sở GDĐH thực hiện quyền tự chủ ở mức độ cao hơn phù hợp với năng lực, kêt quả xếp hạng và kết quả kiểm định chất lượng giáo dục. 2. Cơ sở GDĐH không còn đủ năng lực thực hiện quyền tự chủ hoặc vi phạm pháp luật trong quá trình thực hiện quyền tự chủ, tùy thuộc mức độ, bị xử lí theo quy định của pháp luật.Về học thuật, lần đầu tiên các trường được tư chủ xây dựng, thẩm định, ban hành CTĐT trình độ cao đẳng, đại học, thạc sĩ, tiến sĩ; tự chủ xác định chỉ tiêu tuyển sinh; tự in phôi bằng, cấp bằng cho tất cả các trình độ mà trường đào tạo.
} 
phải công khai, được kiểm soát chặt chẽ và đảm bảo quyền lợi của người học.

Để phù hợp hơn với thực tiễn GDĐH Việt Nam, Luật đã bổ sung quy định cụ thể hơn (Điều 16) về hội đồng trường (là một thiết chế không thể thiếu) đối với cơ sở GDĐH công lập so với quy định tại Điều 53 của Luật giáo dục. Hoạt động của hội đồng trường tạo ra cơ chế kiểm soát quyền lực, giám sát hoạt động điều hành của người đứng đầu cơ sở nhằm tránh tình trạng độc đoán, mất dân chủ.

Nghi định số 186/2013/ND-CP ngày 17/11/2013 của Chính phủ về Đại học Quốc gia được xem là bước đột phá trong tư duy của nhà nuớc về bảo đảm tính độc lập nhiều hơn cho trường đại học công. Mặc dù chưa đạt tới mức tư trị hay nhu các tập đoàn nhung tổ chưc $Đ H Q G$ có quyền tư chủ rất cao trong cung cấp dịch vu GDĐH, nhất là trong đào tạo, nghiên cưu, tổ chức cán bô, kế hoach - tài chính và hơp tác quốc tế. So với các loại hình truờng công khác, ĐHQG có được không gian tư chủ rộng nhất, cả quyền tư chủ thưcc chất và tư chủ thủ tuc. Khả năng chủ động cao của ĐHQG có được là nhò được trao quyền theo co chế đặc biệt, được làm việc trục tiếp với Bộ ngành hay co quan của Chính phủ và khi cần có thể báo cáo với Thu tướng. Ngoài ra, là đơn vị đầu mối nhận các chỉ tiêu kế hoạch, ĐHQG có thể chủ động trong hoạch định phát triể ${ }^{20}$.

Quyền tự chủ của các loại hình trường đại học.

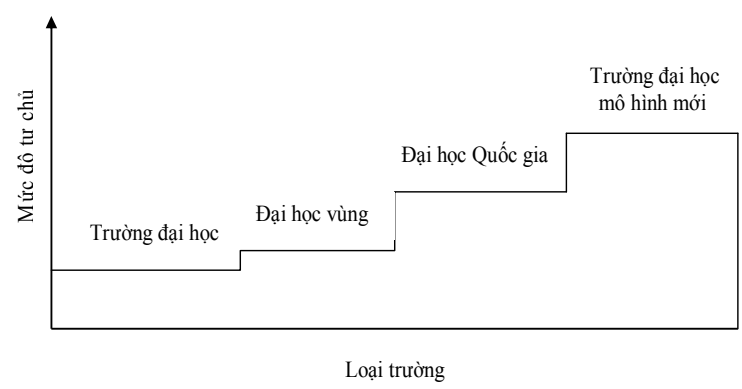

\footnotetext{
10 So với Nghị định 07/2001/NĐ-CP, Nghị định số 186/2013/NĐ-CP đã bổ sung, khắc phục tính chưa triệt để về quyền tự chủ ở một số mặt của ĐHQG, như: trong tuyển sinh, ĐHQG vẫn phải tuân thủ quy chế thi "ba chung" của Bộ GD\&ĐT, trong công tác cán bộ vẫn chưa được quyền bổ nhiệm hiệu trưởng trường thành viên.
}

Phân cấp tự chủ của các trường đại học công lập.

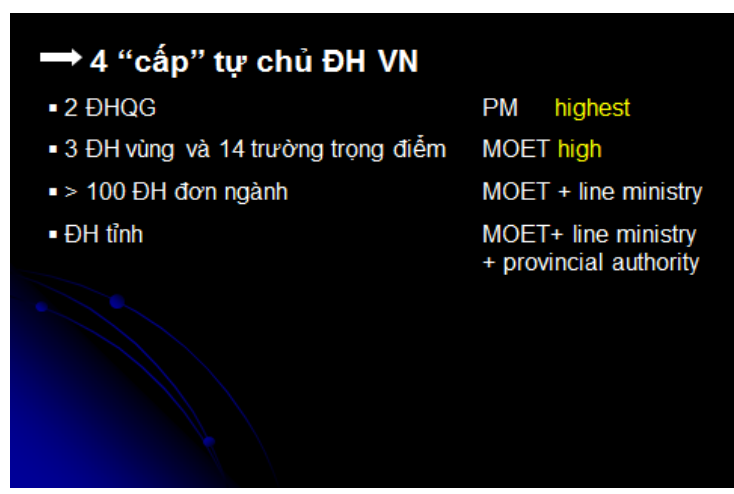

\section{Những bất cập của pháp luật về tự chủ đại học trong thời gian qua}

Trong hơn 2 thập kỷ vừa qua, vấn đề trao quyền tự chủ, cho các cơ sở GDĐH được nhắc đến ngày càng nhiều qua hệ thống các văn bản và những bất cập trong quản lí hệ thống GDĐH cũng được dần tháo gỡ. Tuy nhiên, hệ thống văn bản quy phạm về TCĐH vẫn tồn tại nhiều hạn chế, bất cập cần được quan tâm khắc phục. Cụ thể như sau:

- Luật Giáo dục 1998 quy định các nhóm quyền đã bao quát được nội hàm tổ chức đại học tự chủ, tuy có "mở rộng" phạm vi tự chủ ở nội dung hợp tác nhưng lại không xác lập một nội dung quan trọng là quyền tự chủ học thuật của cá nhân. Điều này phản ánh nhận thức chưa đúng mức về vai trò của tổ chức đại học và đối tượng học thuật. Sự khiếm khuyết này là nguyên nhân làm cho quyền tự chủ thiếu "tinh thần tự chủ" và bị "khập khiễng". Việc chưa xác lập quyền tự chủ học thuật trực tiếp và cụ thể được xem là nguyên nhân làm cho quyết định học thuật thường bị "lu mờ", "nhỏ bé" trước quyết định hành chính; hạn chế việc phát huy khả năng chủ động và trách nhiệm học thuật của nhà trường và cá nhân. Ngoài ra, luật cũng chưa xác lập cụ thể khung pháp lí tự chủ về đánh giá (mặc dù luật đã quy định "tự đánh giá chất lượng giáo dục" (Điều 58) nhưng chưa đủ bảo đảm sự chủ động đánh giá thực sự). 
Ngoài ra, việc quy định đan xen quyền tự chủ với tự chịu trách nhiệm không chỉ dẫn đến sự nhầm lẫn mà còn gây khó khăn cho sự phân định giữa chúng ${ }^{11}$; là nguyên nhân của tình trạng không ít trường đại học cố tận thu trong khi xao lãng trách nhiệm sử dụng hiệu quả nguồn lực. Cũng có không ít quy định chưa bảo đảm tự chủ một cách triệt để và đi kèm với những quy định ràng buộc làm cho quyền tự chủ không thể trực tiếp đi vào cuộc sống và bị lệ thuộc vào sự hướng dẫn, cơ cấu và phân phối lại theo ý chí chủ quan của bộ ngành $^{12}$.

- Các Nghị định số 31-CP và Nghị định số 32- $C P$ không ghi nhận quyền tự chủ nào đối với Đại học vùng. Về mặt pháp lý, đại học vùng hưởng quyền tự chủ "ngang bằng" với một trường đại học trực thuộc nó. Thẩm quyền trội hơn mà một đại học vùng có được, về bản chất là quyền chia lại, không tương xứng với vị thế một loại hình trường gồm nhiều trường đại học trực thuộc. Do vậy, việc thực thi quyền tự chủ của đại học vùng có thể "phương hại" đến khả năng chủ động của các trường đại học thành viên.

- Điều lệ Truờng đại học 2003 đã ghi nhận 7 nhóm quyền tự chủ đối với loại hình trường đại học nhưng trên thực tế không đảm bảo khả năng chủ động bởi quyền chủ quản của bộ ngành cũng được quy định ngay trong Điều lệ.

- Luật Giáo duc 2005 mặc dù ghi nhận quyền tự chủ của trường đại học nhưng mới chỉ là khung nên phải đợi ban hành các văn bản dưới luật để rõ nội hàm của các điều

\footnotetext{
${ }^{11}$ Chẳng hạn, Quy định về huy động, quản lí, sử dụng các nguồn lực ở Điều 60, Khoản 4: Một trường được chủ động "huy động" hay "kiếm tiền" là khả năng tự quyết định trong khi "quản lí" và "chi tiêu" hay "xài tiền" theo cách có hiệu quả lại là khả năng về tự chịu trách nhiệm.

${ }^{12}$ Cụ thể như: việc quy định trường đại học được tự chủ "xây dựng chương trình" nhưng bị giới hạn bởi quy định kèm theo là "đối với các ngành nghề được phép đào tạo" hay việc được tự chủ trong "hợp tác" nhưng phải "theo quy định của Chính phủ" (Điều 60, Khoản 1,5 ) là minh chứng về sự tự chủ không triệt để và khả năng chi phối cao của các cơ quan quản lí nhà nước đối với hoạt động của trường đại học.
}

khoản này. Ngoài ra, theo quy định của Luật thì Nhà nước vẫn đóng vai trò kiểm soát rất lớn cũng như nhiều quy định trái chiều của luật đã gây ảnh hưởng, khó khăn trong việc triển khai thực hiện $\mathrm{TC}^{13}$.

- Quyết định 121/2007/QĐ-TTg các trường đại học trọng điểm được quyền tự chủ tăng thêm nhưng không bền vững vì các trường này được Nhà nước chọn theo từng thời kỳ.

- Luật GDĐH 2012 được xem là cơ sở pháp lí quan trọng để đổi mới GDĐH Việt Nam và cho dù quyền tự chủ của các trường đại học được nêu rõ ràng trong một điều luật riêng nhưng vẫn chưa phải là một bước ngoặt có khả năng tạo ra sự đột phá, vì: 1) Sự kiểm soát của nhà nước vẫn còn rất chặt chẽ về sứ mạng, vị trí, quyền tự chủ phụ thuộc vào năng lực và dựa trên kết quả xếp hạng (Điều 32, 53). Cùng với phân tầng cố định theo luật, Chính phủ/Bộ xếp hạng đại học và kiểm định, Luật cũng quy định mức độ tự chủ khác nhau giữa các trường và để ngỏ khả năng "thu hồi quyền tự chủ". Quyền tự chủ của các trường hoàn toàn phụ thuộc vào những quyết định của nhà nước liên quan việc xác định xem cơ sở giáo dục xứng đáng được trao quyền tự chủ đến đâu. Và sự phân tầng trên dưới có tính chất cố định bằng pháp luật, sự xếp hạng cao thấp có tính chất lâu dài bằng văn bản của người đứng đầu Chính phủ cùng với những mức độ ưu đãi/tự chủ khác nhau theo các tiêu

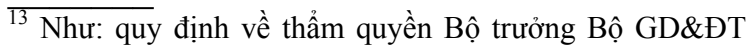
về: chương trình khung cho từng ngành đào tạo, bổ nhiệm hiệu trưởng, chế độ lương và các phụ cấp theo quy định của Chính phủ... "Trên cơ sở thẩm định của Hội đồng quốc gia thẩm định ngành về chương trình giáo dục đại học, Bộ trưởng Bộ GD\&ĐT quy định chương trình khung cho từng ngành đào tạo đối với trình độ cao đẳng, trình độ đại học bao gồm cơ cấu nội dung các môn học, thời gian đào tạo, tỷ lệ phân bổ thời gian đào tạo giữa các môn học, giữa lí thuyết với thực hành, thực tập. Căn cứ vào chương trình khung, trường cao đẳng, trường đại học xác định chương trình giáo dục của trường mình" (Điều 41): "Hiệu trưởng là người chịu trách nhiệm quản lí các hoạt động của nhà trường, do cơ quan nhà nước có thẩm quyền bổ nhiệm, công nhận" (Điều 54); "Nhà giáo được hưởng tiền lương, phụ cấp ưu đãi theo nghề và các phụ cấp khác theo quy định của Chính phủ” (Điều 81).
} 
chí tầng trên/dưới, hạng cao/thấp, công lập/tư thục, trong/ngoài nước sẽ dẫn đến cuộc cạnh tranh không bình đẳng giữa các trường ${ }^{14}$. 2) Về tổ chức, nhân sự: luật quy định cơ quan chủ quản quyết định thành lập, chia tách, sát nhập, giải thể trường; bổ nhiệm Chủ tịch hội đồng, hiệu trưởng; quyết định biên chế, lương... 3) Về tài chính, Bộ GD\&ĐT vẫn xét duyệt chỉ tiêu tuyển sinh và tổ chức kì thi "ba chung"; cơ chế xin - cho còn hiện diện trong quy định việc mở ngành, in phôi bằng của các trường đại học.

Cùng với hạn chế mức độ quyền tự chủ của các trường, Luật cũng còn nhiều điểm chưa phù hợp với tinh thần TCĐH hoặc một số quy định còn chưa rõ ràng nên khó khăn trong thực thi. Khái niệm tự chủ cũng chưa được hiểu đúng, dẫn đến từng khía cạnh của quyền tự chủ đều bị hạn chế hoặc chỉ được trao một cách hình thức: quyền tự chủ vừa được giao ở điều này nhưng thường xuyên bị hạn chế (thu hẹp) bởi những điều khoản khác, thậm chí mâu thuẫn ngay giữa hai khoản trong cùng một điều luật ${ }^{15}$. Quan niệm về tự chủ như trên kéo theo quan điểm trao cho nhà nước thẩm quyền rất lớn đối với toàn bộ hoạt động của các trường và cả ba phương diện tự chủ của nhà trường đều bị hạn chế một cách tối đa. Nhìn chung, quyền tự chủ

\footnotetext{
${ }^{14}$ Một thực tế là: các trường ở tầng dưới/thứ hạng thấp/ưu đãi kém sẽ gặp nhiều khó khăn trong thực hiện quyền tự chủ, còn những trường đã được cố định ở tầng cao/thứ hạng cao/ưu đãi cao cũng sẽ mất dần động cơ phấn đấu.

${ }_{15}$ Chẳng hạn: 1/ Khái niệm "tư chủ" ở đây không giống như quan niệm phổ biến ở phương Tây, tự chủ không được xem là quyền đương nhiên của cơ sở GDĐH mà phụ thuộc vào năng lực đồng thời dựa trên kết quả xếp hạng và kiểm định (Điều 32,53 ) và cả hai việc này đều do nhà nước kiểm soát. 2/ Về việc xếp hang, tuy Luật GDĐH đã có quy định về việc công nhận kết quả xếp hạng (Điều 9 , Khoản 5) nhưng chưa quy định rõ ai là người thực hiện. Mặc dù việc kiểm định độc lập đã được đặt ra từ lâu, nhưng theo Luật GDĐH 2012 thì hoàn toàn do Bộ GD\&ĐT kiểm soát, từ khâu ban hành chuẩn đối với cơ sở giáo dục và chương trình giáo dục; yêu cầu tối thiểu để thực hiện chương trình; quy trình và chu kì kiểm định; nguyên tắc, điều kiện, và tiêu chuẩn của tổ chức, cá nhân hoạt động kiểm định chất lượng; cấp giấy, thu hồi giấy chứng nhận kiểm định; quyết định thành lập hoặc cho phép hoạt động kiểm định (Điều 52, Khoản 3).
}

được cụ thể hoá trong luật ${ }^{16}$ mới chỉ ở mức độ tự chủ thủ tục trong khi đó tự chủ thực chất liên quan chủ yếu đến tự chủ quản trị và cùng với một hệ thống giám sát minh bạch, hiệu quả mới thực sự là những vấn đề cần thiết để nâng cao hiệu quả, chất lượng của GDĐH Việt Nam. Một điểm mới khác của Luật là quy định trường đại học có hội đồng trường (do hiệu trưởng/ giám đốc đại học làm chủ tịch) và quá trình thực hiện TCĐH thực chất là quá trình chuyển giao quyền lực tập trung ở bộ chủ quản và hiệu trưởng sang hội đồng trường nhưng trên thực tế hội đồng trường công đóng vai trò hình thức và tư vấn hơn là một hội đồng quyền lực (đối với HĐQT trường tư: quyền tự chủ là quyền của những cổ đông lớn). Hội đồng trường không có quyền sáp nhập/chia tách trường mà quyền này thuộc về người có thẩm quyền quyết định thành lập hoặc cho phép thành lập cơ sở GDĐH. Đối với các trường đại học công lập, hội đồng trường được trao quyền rất lớn nhưng không có quyền bầu và miễn nhiệm hiệu trưởng/giám đốc. Mặc dù không phải chịu nhiều ràng buộc như các trường công lập nhưng thực hiện quyền tự chủ của các trường đại học tư thục cũng bị hạn chế nhiều mặt ${ }^{17}$ và thực chất là quyền của những cổ đông lớn mà không phải của các nhà chuyên môn. Do Luật chưa quy định rõ mối quan hệ giữa tổ chức Đảng với hội đồng trường nên hội đồng trường chỉ mang tính hình thức, không có thực quyền.

- Nghị định 43/2006/ND-CP bên cạnh những mặt tích cực cũng bộc lộ những hạn chế trong việc phải tuân thủ mức trần học phí do Nhà nước quy định tại Nghị định 49/2010/NĐCP (đã hết hiệu lực thi hành từ 01/12/2015) trong khi mức học phí quy định chưa đảm bảo bù đắp đủ chi phí hoạt động cần thiết, chưa sát

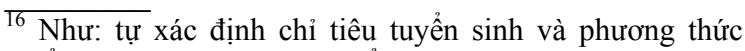
tuyển sinh, tự xây dựng, thẩm định và ban hành CTĐT (trong khuôn khổ quy định của Bộ), hoặc tự in phôi bằng, cấp văn bằng cho người học...

${ }^{17}$ Nhu: việc bầu hiệu trưởng sau khi được bầu phải được cơ quan có thẩm quyền của nhà nước công nhận.
} 
với yêu cầu chi phí đặc thù của từng ngành, nghề đào tạo cũng như yêu cầu về chất lượng, thương hiệu của từng trường. Cơ chế phân bổ NSNN còn mang tính bình quân, dựa trên các yếu tố đầu vào mà chưa gắn với kết quả, hiệu quả hoạt động. Việc quy định triển khai thực hiện xã hội hóa và liên doanh liên kết còn chưa cụ thể, rõ ràng;cấp trên vẫn giao chỉ tiêu biên chế sự nghiệp nên tự chủ về nhân sự bị hạn chế... Nghị định 43/2006/NĐ-CP mới chỉ đáp ứng được vấn đề quản lí, quản trị của cơ sở GDĐH mà chưa đi sâu vào nội dung cơ bản của nội hàm tự chủ, tự chịu trách nhiệm của GDĐH.

Để khắc phục những bất cập trên, Chính phủ đã ban hành Nghị quyết số $77 / \mathrm{NQ}-\mathrm{CP}$ ngày $24 / 10 / 2014$ về thí điểm đổi mới cơ chế hoạt động đối với các cơ sở GDĐH công lập giai đoạn 2014-2017 và Nghị định số 16/2015/NĐ-CP ngày 14/02/2015 về cơ chế tự chủ của đơn vị sự nghiệp công lập (thay thế Nghị định 43/2006/NĐ-CP) nhằm khuyến khích, tạo điều kiện cho các cơ sở GDĐH công lập có đủ điều kiện, cam kết tự đảm bảo kinh phí hoạt động chi thường xuyên và chi đầu tư được thực hiện tự chủ, tự chịu trách nhiệm toàn diện về nhiệm vụ đào tạo, $\mathrm{NCKH}$, tổ chức bộ máy, nhân sự và tài chính ${ }^{18}$. Mặc dù việc ban hành Nghị định 16/2015/NĐ-CP được cho là kịp thời đáp ứng yêu cầu đổi mới, phát triển của hoạt động sự nghiệp công trong nền kinh tế thị trường định hướng XHCN. Nhiều quy định văn bản pháp lí chưa kịp thay đổi để hỗ trợ các trường đại học tự chủ (Nghị quyết 77/NQ-CP chỉ mới là thí điểm nên các văn bản pháp luật không thay đổi theo). nên thực hiện thí điểm $\mathrm{TC} Đ H$ trong thời gian vừa qua được ví như vừa tự chủ vừa trói chân.

Nhìn chung, thông qua các văn bản pháp quy Nhà nước và Bộ GD\&ĐT đã chú trọng và cố gắng tạo ra hành lang pháp lí cho quyền tự

\footnotetext{
$\overline{18}$ Một số trường đại học top đầu như: Bách khoa Hà Nội, Ngoại thương, Học viện Tài chính đã từng bước được giao tự chủ một phần về tài chính.
}

chủ của các cơ sở GDĐH. Tự chủ của các đại học trên các văn bản pháp lí đã có những thay đổi theo hướng các địa học ngày càng được giao nhiều quyền hơn. Quá trình hoàn thiện quyền tự chủ cho thấy chủ trương nhất quán của Đảng và Nhà nước, vừa khẳng định vừa tăng quyền tự chủ cũng như sự chuyển biến trong nhận thức về vấn đề trao quyền cho trường đại học từ rất e ngại đến thừa nhận chính thức về mặt pháp lí; góp phần đưa hệ thống đại học Việt Nam bước ra khỏi thời kì khó khăn và đem lại nhiều thành tựu mới. Mặc dù nhận thức pháp lí về tự chủ có bước tiến nhưng còn thiếu triệt để, nhất quán và sự đồng bộ trong các chủ trương chính sách $^{19}$. Quyền tự chủ được xác lập theo quan niệm "cho" hay "phân" lại quyền hơn là dựa trên địa vị pháp lí độc lập và mặc dù bao quát được nhiều nội dung tự chủ nhưng vẫn còn thiếu một số quyền trọng yếu khác. Vẫn còn tình trạng một số quy định trong các văn bản pháp quy còn chung chung, chưa thực sự rõ ràng và chưa đầy đủ nên hiệu quả của các văn bản này chưa được như mong muốn, các quyền tự chủ vẫn chưa thật sự phát huy hết tác dụng. Quy định giao tự chủ vẫn nặng xin - cho và các cơ sở GDĐH dường như vẫn mong muốn nhận được phân cấp mạnh mẽ hơn và được tăng thêm quyền tự chủ (nhất là trong các lĩnh vực quản lí tài chính, bộ máy, nhân sự, tuyển sinh, trang thiết bị, cơ sở vật chất). Ngoài ra, quyền tự chủ do luật định cũng phải chịu "thách thức" từ các văn bản dưới luật do cơ quan hành chính quy định. Việc quy định quyền tự chủ đan xen với tự chịu trách nhiệm và bị giới hạn bởi tập quán lập pháp với “quy định kép”, một quy định có kèm theo quy định ràng buộc khác đã làm cho quyền tự chủ bị lẫn lộn và không thể trực tiếp đi vào cuộc sống. Đồng thời, việc tăng cường quyền tự chủ theo cách cục bộ, cá biệt và dựa

\footnotetext{
${ }^{19}$ Phần lớn những ý kiến khi bàn đến $\mathrm{TC} Đ H$ thường chỉ nói đến khía cạnh tài chính (như: xác định mức học phí, vay tiền hoặc gây quỹ...); tuy nhiên, có thể các trường đại học lại có nhiều tự chủ hơn trong các mặt tổ chức, xây dựng lực lượng của nhà trường...
} 
trên ưu tiên chính sách ngắn hạn có nguy cơ tạo ra đặc quyền và sự bất bình đẳng, cạnh tranh không lành mạnh giữa các trường. Những bất cập này được xem là một nguyên nhân hạn chế tính tự chủ, kéo theo hạn chế của chất lượng đào tạo. Thực tế cho thấy: việc triển khai cơ chế
TCĐH đang gặp mâu thuẫn, bất cập giữa một bên là những điều kiện biên (luật, chính sách, $\mathrm{TNXH}$, truyền thống, chất lượng...) với một bên là những điều kiện thực tế (luật không nhất quán, thiếu đồng bộ, bộ máy hành chính...).

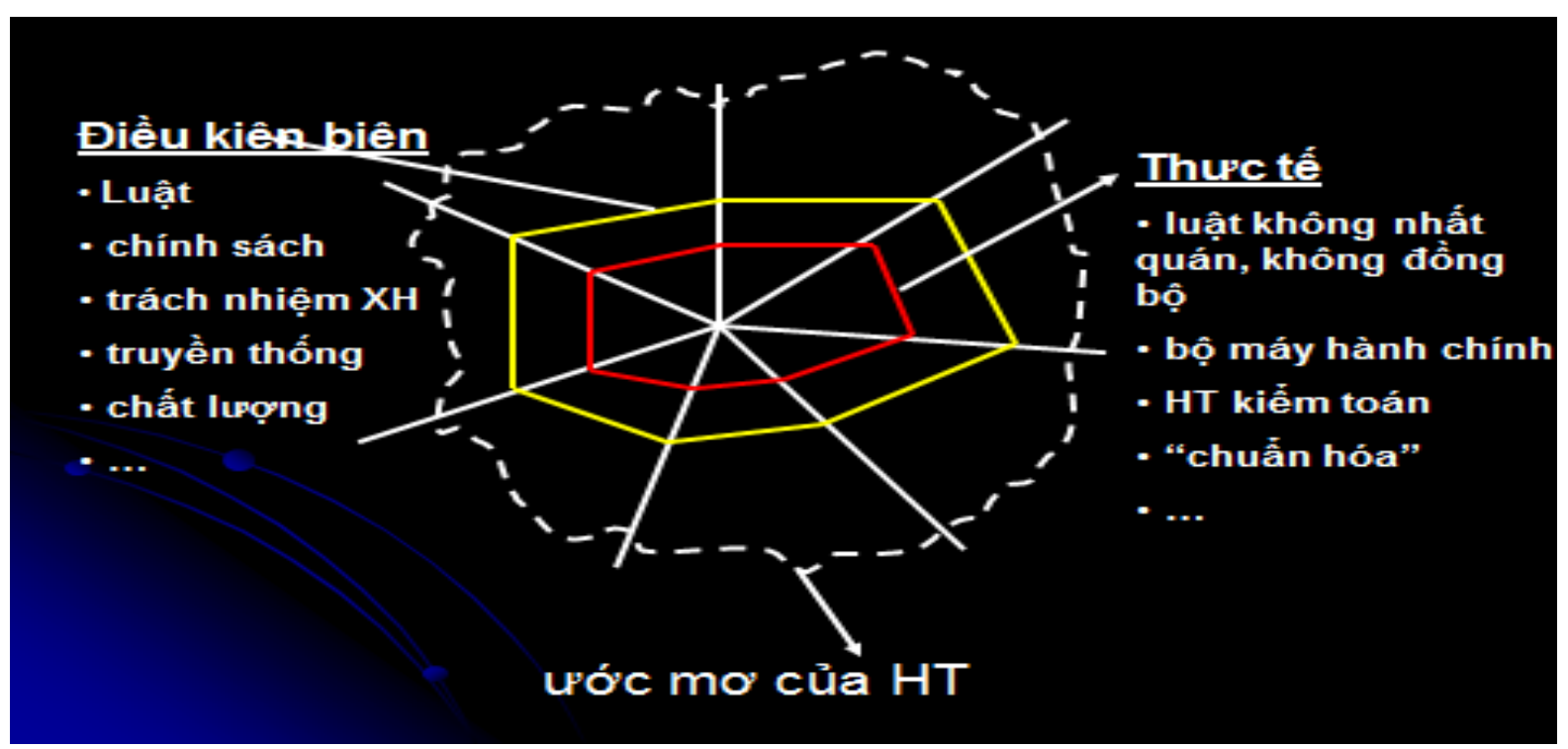

\section{Kết luận}

Tự chủ, tự chịu trách nhiệm là nội dung quan trọng trong bước đi của quá trình cải cách GDĐH nhằm đáp ứng nhu cầu xã hội và hội nhập quốc tế. Được đưa vào thực tế GDĐH Việt Nam trong hơn 2 thập kỷ nay cùng với sự hình thành và phát triển của quản lí chuyên môn, TCĐH đang được triển khai thực hiện tích cực ở Việt Nam với hàng loạt cơ chế, chính sách tạo cơ sở pháp lí, đặc biệt là các chính sách về tự chủ tài chính được ban hành và triển khai thực hiện. Luật giáo dục 2005, Luật GDĐH 2012 và nhiều VBQPPL đã ghi nhận, trao quyền tự chủ, tự chịu trách nhiệm cho các trường đại học. Để đảm bảo việc thực hiện tự chủ của các cơ sở GDĐH thành công theo chủ trương, chính sách của Đảng - Nhà nước, thúc đẩy phát triển sự nghiệp GDĐH, nâng cao chất lượng dịch vụ, Chính phủ đã ban hành nhiều cơ chế, chính sách tự chủ tài chính. Các cơ chế tự chủ, tự chịu trách nhiệm về thực hiện nhiệm vụ, tổ chức bộ máy, biên chế và tài chính đối với các cơ sở GDĐH công lập cũng liên tục được ban hành, sửa đổi, bổ sung phù hợp với yêu cầu thực tiễn, tạo tiền đề pháp lí cho tiến trình và những kết quả quan trọng trong việc chuyển đổi cơ chế quản trị đại học theo mô hình quản lí theo cơ chế báo cấp sang cơ chế tự chủ ở Việt Nam.

Đặc biệt, ngày 19/11/2018, tại Kì họp thứ 5, Quốc hội khóa XIV đã thông qua "Luật Sửa đổi, bổ sung một số điều của Luật giáo dục đại học" (gọi tắt là "Luật GDĐH sửa đổi", có hiệu lực thi hành từ ngày $01 / 7 / 2019$ ) . Luật GDĐH sửa đổi đã sửa đổi căn bản, toàn diện Luật GDĐH 2012. Cụ thể là: 1) So với Luật GDĐH 2012, Luật GDĐH sửa đổi đã chỉnh sửa, bổ sung (các khoản, mục, điểm) 36/73 điều; Luật mới bổ sung thêm 02 điều (Điều 1 và Điều 16a). Luật GDĐH sửa đổi đã bao quát hầu hết các vấn đề cần sửa đổi, bổ sung đối với Luật 
GDĐH 2012 nhưng vẫn giữ nguyên cơ cấu, thứ tự (các chương, điều) của Luật GDĐH 2012. 2) Địa vị pháp lí của ĐHQGHN tiếp tục được duy trì (giữ nguyên Điều 8 của Luật GDĐH 2012). 3) Luật GDĐH sửa đổi có nhiều nội dung mới nhằm gỡ bỏ những "nút thắt" cản trở GDĐH phát triển, như: Không có sự phân biệt trong văn bằng của các hình thức đào tạo khác nhau; Trường đại học được tự chủ mở ngành; Chủ tịch hội đồng trường không cần là tiến sĩ. Luật GDĐH sửa đổi cũng thể hiện sáu điểm đột phá đối với GDĐH là: Mở rộng phạm vi và nâng cao hiệu quả tự chủ đại học; Đổi mới quản trị đại học; Đổi mới quản lí đào tạo; Đổi mới quản lí nhà nước trong điều kiện tự chủ đại học; Sửa đổi quy định về giảng viên theo hướng đảm bảo chuẩn chất lượng, giao quyền tự chủ cho cơ sở GDĐH trong việc bổ nhiệm, suy tôn các chức danh giảng viên; Về tài chính, tài sản trong GDĐH. Hy vọng rằng, với nhiều điểm mới và những thay đổi đột phá về cơ chế, chính sách GDĐH thu hút sự quan tâm đặc biệt của dư luận, Luật GDĐH sửa đổi sẽ tác động tạo ra thay đổi, chuyển biến tích cực trong tiến trình hoàn thiện cơ chế quản trị đại học tự chủ; góp phần thực hiện mục tiêu đổi mới căn bản, toàn diện giáo dục đào tạo nước ta.

\section{Tài liệu tham khảo}

[1] Callahan M. 1995. Academic Freedom, Autonomy and Accountability. Largely abstracted from: OCUA, Some Perspectives on Academic Freedom, Autonomy and Accountability. Task Force on Resource Allocation, Ontario Council on University Affairs. $<$ http://cclp.mior.ca/Compex/AcFreeAccount Aut M Sgp.pdf $>$

[2] Vũ Thị Phương Anh, Tự chủ trong Luật giáo dục đại học của Việt Nam: Cần có tự chủ thực chất ttps://hocthenao.vn/2014/08/14/tu-chu-trong-luatgiao-duc-dai-hoc-cua-viet-nam-can-co-tu-chuthuc-chat-vu-thi-phuong-anh/

[3] Báo cáo của Hội đồng Giáo dục UNESCO về Giáo dục thế kỷ XXI, 1997 (Khuyến nghị của UNESCO về vị thế của giáo viên và giảng viên đại học.

\title{
Mechanisms of Authority of University and Authority Complete Legislative University Law in Vietnam
}

\section{Do Duc Minh}

VNU Inspection and Legislation Department, 144 Xuan Thuy, Cau Giay, Hanoi, Vietnam

\begin{abstract}
The paper clarifies the basics of university autonomy, outlines the process of institutionalizing university autonomy and implementing university autonomy in the past, analyzing constraints, Inadequacy of the law and clarification of the need to improve the law of university autonomy, meeting the requirements of radical and comprehensive reform of higher education today.
\end{abstract}

Keywords: University Autonomy, Higher Education Reform, Vietnam. 